\title{
Influência do tempo de injeção e degradação in vitro nas propriedades mecânicas, morfológicas e térmicas do poli(3-Hidroxibutirato)
}

\author{
Influence of injection time and in vitro degradation \\ in the mechanical, morphological and thermal \\ properties of poly (3-hydroxybutyrate)
}

\author{
Marcio Briesemeister ${ }^{1}$, Katiusca Wessler ${ }^{1}$,
} Márcia Adriana Tomaz Duarte ${ }^{2}$

\begin{abstract}
${ }^{1}$ UNISOCIESC, Mestrado em Engenharia Mecânica, Rua Albano Schmidt, 3333, CEP 89206-001, Joinville, SC, Brasil. ${ }^{2}$ DBM Eletrotech, Rua Xavantes, 54, CEP 89203-900, Joinville, SC, Brasil. e-mail:marcio.brie@gmail.com, katiusca.wessler@unisociesc.com.br, marciaatomaz@gmail.com
\end{abstract}

\section{RESUMO}

O PHB é um polímero biorreabsorvível e biodegradável, proveniente de fontes naturais e renováveis, sendo compatível para aplicações tanto na indústria farmacêutica como na biomédica. O presente estudo visa avaliar a influência do tempo de injeção e do tempo de degradação in vitro nas propriedades mecânicas, morfológicas e térmicas do Poli(3-hidroxibutirato) (PHB). Para tanto, foram injetados corpos de prova de tração e impacto com diferentes tempos de injeção, sendo submetidos a diferentes tempos de degradação e sujeitos às seguintes caracterizações: calorimetria exploratória diferencial (DSC), análise termogravimétrica (TG), tração, microscopia óptica com luz polarizada, microscopia eletrônica de emissão de campo (FEG), impacto e dureza. À medida que o tempo de injeção foi ampliado e o tempo de degradação avançava, foram observadas as seguintes alterações: aumento de até $18,9 \%$ na cristalinidade; princípio de degradação térmica; redução na tensão máxima de até $12,8 \%$; evidencias de degradação hidrolítica, aumento de até $29,9 \%$ na resistência ao impacto e aumento de $3,5 \%$ da dureza. Sendo assim, concluiu-se que diferentes tempos de injeção combinado com a degradação in vitro influenciaram nas propriedades finais do PHB.

Palavras-chave: Poli(3-hidroxibutirato); Degradação in vitro; Moldagem por Injeção; Tempo de Injeção.

\section{ABSTRACT}

PHB is a biodegradable bioresorbable polymer from natural and renewable sources and is compatible for applications in both the pharmaceutical and biomedical industries. The present study aims to evaluate the influence of injection time and in vitro degradation time on the mechanical, morphological and thermal properties of Poly (3-hydroxybutyrate) (PHB). For this, tensile and impact specimens with different injection times were injected, subjected to different degradation times and subjected to the following characterizations: differential scanning calorimetry (DSC), thermogravimetric (TG) analysis, traction, polarized optical microscopy, field emission gun (FEG), impact and hardness. As the injection time was extended and the degradation time was advanced, the following changes were observed: up to $18.9 \%$ increase in crystallinity; principle of thermal degradation; reduction in maximum tension of up to $12.8 \%$; evidence of hydrolytic degradation, up to $29.9 \%$ increase in impact resistance and an increase of $3.5 \%$ in hardness. Thus, it was concluded that different injection times combined with in vitro degradation influenced the final PHB properties.

Keywords: Poly (3-hydroxybutyrate); In vitro degradation; Injection Molding; Injection time.

\section{INTRODUÇÃO}

Há uma demanda crescente por soluções que minimizem os efeitos negativos provenientes do envelhecimento e de causas antinaturais, soluções que possam contribuir significativamente para a qualidade de vida dos organismos lesionados. Neste contexto, são aplicados os biomateriais como alternativa para recompor estruturas contundidas. Atualmente, a utilização de biomateriais em aplicações ortopédicas é um ramo bastante promissor no universo da engenharia de materiais.

No contexto dos biomateriais, destacam-se os biomateriais poliméricos, os quais apresentam várias 
possibilidades de aplicações na área biomédica, devido à sua biocompatibilidade e biodegradabilidade [1] São aplicados na produção de suturas cirúrgicas, nos sistemas para liberação controlada de fármacos e nos dispositivos ortopédicos como parafusos e pinos [2].

O PHB é um polímero biorreabsorvível e biodegradável, proveniente de fontes naturais e renováveis como milho, celulose, batata e cana de açúcar, bem como, sintetizados por bactérias ou ainda derivados de fontes animais, como a quitosana [3, 4]. Em decorrência de sua característica biocompatível, pode ser utilizado em aplicações médicas como próteses, suturas e dispositivos para liberação de fármacos [3]. É um poliéster termoplástico linear e cristalino, pertencente à família dos poliésteres alifáticos. Possui propriedades mecânicas comparáveis às dos polímeros convencionais, como poliestireno e polipropileno. Apresenta uma elevada taxa de cristalização e um elevado grau de cristalinidade, tornando o material frágil e quebradiço [3]. Sua alta regularidade estrutural, diminui a taxa de absorção pelo organismo, tornando a reabsorção lenta, compatível com a regeneração tecidual $[5,6]$.

No entanto, sua microestrutura e propriedades termomecânicas são fortemente dependentes da massa molecular [7-15]. O PHB apresenta uma janela de processamento bastante estreita em função do polímero degradar logo acima de sua temperatura de fusão [5-7]. A cristalização secundária é outra característica indesejável, a qual regiões amorfas do material solidificado vão se organizando com o passar do tempo em estruturas lamelares, ocasionando aumento da fragilidade [14]. Forças mecânicas envolvidas nas técnicas de processamento, como extrusão e injeção, contribuem para a redução de sua massa molar por meio do cisalhamento das cadeias poliméricas [8-13].

No tocante ao processo de injeção, variações na temperatura do fundido e do molde, pressões de injeção e de recalque, bem como, os tempos de resfriamento e tempos de injeção, constituem as variáveis de processamento que promovem as maiores influências sobre a microestrutura de um produto injetado [9]. A variação do tempo de injeção promove alterações na orientação molecular de um polímero, que por sua vez interfere nas propriedades morfológicas do material. Baixos tempos de injeção promovem altas taxas de cisalhamento e contribuem para a orientação molecular no sentido do fluxo, além de interferir na cristalização do material [10-29].

Quanto à degradação abiótica, na qual a degradação in vitro está inserida, ocorre sem a presença de organismos vivos e uma das reações mais conhecidas é a hidrólise. A cristalinidade é um fator determinante, pois as regiões cristalinas do PHB são impermeáveis à água, retardando o processo de degradação [11].

O presente estudo se justifica, pois, a alta cristalinidade do PHB pode ser controlada pelas taxas de aquecimento e resfriamento [12-29]. A otimização do processamento do PHB, a partir do estado plastificado é imprescindível para ampliar a gama de aplicações, na qual as propriedades finais do PHB estão relacionadas às condições de processamento e aos mecanismos de cristalização desenvolvidos durante o mesmo [5-13]. As variações da estrutura de um polímero em função das variáveis do processo de injeção influenciam na resistência à tração, no módulo de elasticidade, na resistência ao impacto, na dureza, e na estabilidade dimensional [10].

Desta forma, o objetivo do presente estudo é avaliar a influência do tempo de injeção nas propriedades mecânicas, morfológicas e térmicas do $\mathrm{PHB}$, concomitantemente, com o processo de degradação in vitro. Sendo assim, pretende-se demonstrar pontualmente a relação que esta variável do processo de moldagem possui com as propriedades mencionadas.

\section{MATERIAIS E MÉTODOS}

O estudo envolveu a injeção de corpos de prova de tração e impacto, a degradação in vitro e a caracterização das amostras injetadas e do PHB virgem. A seguir são pormenorizadas cada uma das etapas empregadas na metodologia.

\subsection{Material utilizado}

O material utilizado neste estudo foi gentilmente doado pela PHB Industrial S/A, fornecido em forma de pó e, conforme ficha técnica fornecida pela fabricante, o material apresentava as seguintes características: massa molecular (Mw) de $600.000 \mathrm{~g} / \mathrm{mol}$, polidispersão de 2,29 e densidade de 1,22 $\mathrm{g} / \mathrm{cm}^{3}$. 


\subsection{Injeção dos corpos de prova}

A etapa de injeção foi realizada na empresa Sokit, localizada na cidade de Araquari, no estado de Santa Catarina. Foram injetados corpos de prova em PHB para ensaios de tração e impacto com dimensões de acordo com as normas ISO 527-1:2012 e ISO 180:2000.

Utilizou-se uma injetora da marca Haitian modelo SA1200/410, com diâmetro de rosca de $40 \mathrm{~mm}$, $214 \mathrm{~cm}^{3}$ de volume teórico de injeção, força de fechamento de $1200 \mathrm{KN}$ e pressão máxima de injeção de 192 MPa. Os parâmetros de processamento que foram utilizados são apresentados na Tabela 1.

\begin{tabular}{l|c|c}
\cline { 2 - 3 } & Tração & Impacto \\
\hline Tempo de injeção (s) & $3,5,2$ e 10 & $1,1,2$ e 3 \\
\hline Pressão de injeção (MPa) & \multicolumn{2}{|c}{40} \\
\hline Pressão de recalque (MPa) & \multicolumn{2}{|c}{10} \\
\hline Tempo de recalque (s) & 4 \\
\hline $\begin{array}{l}\text { Temperatura de } \\
\text { processamento }\left({ }^{\circ} \mathrm{C}\right) \\
\text { (nas quatro zonas) }\end{array}$ & \multicolumn{2}{|c}{165} \\
\hline Temperatura do molde $\left({ }^{\circ} \mathrm{C}\right)$ & \multicolumn{2}{|c}{25} \\
\hline Tempo de resfriamento $(\mathrm{s})$ & 20 \\
\hline
\end{tabular}

Tabela 1: Parâmetros do processo de injeção dos corpos de prova de tração e impacto

Todas as variáveis controladas do processo de injeção foram estabilizadas, mantendo variável somente o tempo de preenchimento das cavidades do molde. Os corpos de prova de impacto foram injetados com os tempos de 1,2, 2 e 3 segundos. Já para os corpos de prova de tração, os tempos foram de 3, 5,2 e 10 segundos.

\subsection{Degradação in vitro das amostras injetadas}

As amostras dos corpos de prova de tração e impacto foram submetidas à degradação in vitro à temperatura

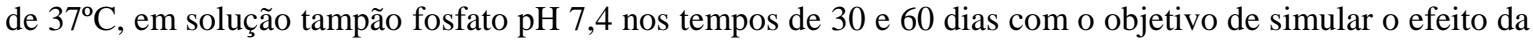
degradação dos materiais ocorrida no organismo vivo, frente aos diferentes tempos de preenchimento dos corpos de prova.

O procedimento foi realizado no laboratório de química da Unisociesc, na cidade de Joinville, no estado de Santa Catarina. Foi utilizado um equipamento QUIMIS banho maria Q215M para manter os corpos de prova na temperatura constante e uniforme de $37^{\circ} \mathrm{C}$.

\subsection{Calorimetria exploratória diferencial (DSC)}

As análises DSC foram realizadas na Pontifícia Universidade Católica de São Paulo, campus de Sorocaba. Foi utilizado um equipamento da marca TA Instruments modelo 2920 Modulated DSC, com massa média de $10 \mathrm{mg}$ e taxa de aquecimento e resfriamento de $10^{\circ} \mathrm{C} / \mathrm{min}$, sob atmosfera de nitrogênio e fluxo de $40 \mathrm{ml} / \mathrm{min}$.

Para obtenção das curvas referentes ao PHB puro e do PHB injetado com corpo de prova de tração, o material foi aquecido de $25^{\circ} \mathrm{C}$ até $200^{\circ} \mathrm{C}$, permanecendo na temperatura por 4 minutos, sendo estes dados utilizados para o primeiro aquecimento. Para o segundo aquecimento, o material foi resfriado até $-30^{\circ} \mathrm{C}$ e posteriormente aquecido até $200^{\circ} \mathrm{C}$, permanecendo na temperatura por 3 minutos.

O grau de cristalinidade do material foi obtido por meio da Equação 1, considerando que a entalpia de fusão para PHB $100 \%$ cristalino é de $\Delta H f^{\circ}=146 \mathrm{~J} / \mathrm{g}$ [21].

$$
\% \text { cristalinidade }=\frac{\Delta \mathrm{Hf}-\Delta \mathrm{Hc}}{\Delta \mathrm{Hf}^{\circ}} \times 100
$$


Na Figura 1, é apresentada a região dos corpos de prova de tração, onde foram retiradas as amostras para os ensaios.

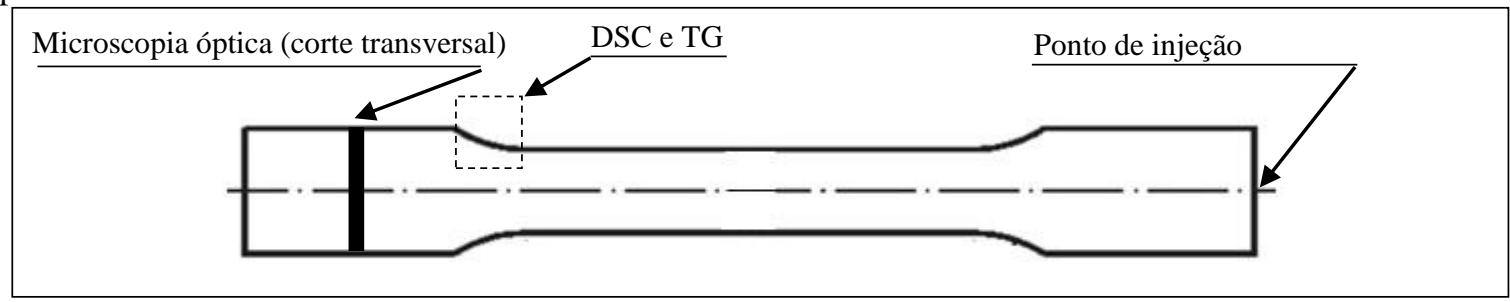

Figura 1: Regiões do corpo de prova de tração de onde foram obtidas as amostras de DSC, TG e microscopia óptica

\subsection{Análise termogravimétrica (TG)}

As análises termogravimétricas foram realizadas no laboratório de materiais da Unisociesc em Joinville, utilizando um instrumento da TA Instruments modelo Q50. A taxa de aquecimento empregada foi de $10^{\circ} \mathrm{C} /$ minuto, em atmosfera de nitrogênio com temperatura de 25 a $600^{\circ} \mathrm{C}$.

A região dos corpos de prova de tração de onde foram retiradas as amostras para os ensaios de TG é a mesma apresentada na Figura 1.

\subsection{Ensaio de tração}

Os ensaios de tração foram realizados no Centro de Aplicações Mecânicas e Gestão Industrial (CAMEGI) da Universidade da Região de Joinville (UNIVILLE), utilizando uma máquina universal de ensaios EMIC DL 10000/700, equipada com uma célula de carga de $500 \mathrm{~N}$, utilizando velocidade de ensaio de $50 \mathrm{~mm} / \mathrm{min}$ e comprimento útil de $50 \mathrm{~mm}$, conforme requisitos da norma ISO 527-1:2012.

Foram ensaiadas 5 amostras de cada grupo com seus respectivos tempos de injeção de 3, 5,2 e 10 segundos, totalizando 45 amostras com o objetivo de obtenção da tensão máxima, deformação na ruptura e módulo de elasticidade.

\subsection{Microscopia óptica com luz polarizada}

As amostras foram obtidas a partir do corte transversal dos corpos de prova de tração na região oposta ao ponto de injeção, conforme apresentado na Figura 1. Foi utilizado um micrótomo do Laboratório de Polímeros da Unisociesc, unidade Joinville para a obtenção das lâminas com espessura aproximada de $10 \mu \mathrm{m}$.

As imagens foram geradas em um microscópio óptico da marca Nikon modelo Eclipse E800, acoplado a uma câmera digital Nikon DS-Ril, instalado no Laboratório de Biomateriais da Pontifícia Universidade Católica de Sorocaba no estado de São Paulo.

\subsection{Microscopia eletrônica de emissão de campo (FEG)}

A técnica de microscopia eletrônica de emissão de campo foi empregada para verificar se houve modificação morfológica através da superfície de fratura dos corpos de prova de tração, em função dos diferentes tempos de injeção.

As amostras foram metalizadas com ouro (Dentan Vacuum Desk $V$ ) e analisadas em um microscópio eletrônico de emissão de campo (JEOL JSM-6701F), operado a 10kV. A caracterização foi realizada no laboratório de materiais da Universidade do Estado de Santa Catarina (UDESC) em Joinville.

\subsection{Ensaio de impacto izod}

Os ensaios de impacto izod foram realizados no laboratório de polímeros da Unisociesc em Joinville, conforme requisitos da norma ISO 180:2000. Foi utilizado uma máquina da marca Microtest, equipada com pêndulo de 2 J. Testou-se 10 corpos de prova com dimensões de 4x10x80mm com entalhe, para os tempos de injeção de 1,2, 2 e 3 segundos. 


\subsection{Ensaio de dureza}

Os ensaios mecânicos de dureza Shore D, foram realizados no laboratório de polímeros da Unisociesc em Joinville, com o emprego do equipamento WULTEST SD 300, utilizando durômetro Shore D com tempo de espera para leitura de 10 segundos, conforme as recomendações da norma ASTM D2240/75.

Em um mesmo corpo de prova de tração foram realizadas 5 leituras de dureza em diferentes posições de uma mesma face.

\subsection{Análise estatística}

Foram analisadas estatisticamente se as diferentes média dos resultados, ocasionadas por diferentes tempos de injeção nas amostras, combinadas com suas respectivas dispersões, representaram diferenças significativas.

Para as análises, foi utilizado o teste de hipóteses, denominado de teste T, apropriado para comparar dois conjuntos de dados quantitativos com distribuição normal, em termos de seus valores médios [18]. Juntamente com o teste $\mathrm{T}$, foi empregada a análise de variância, denominada de ANOVA, usada para comparar médias contendo distribuição normal, quando houver dois ou mais níveis de um único fator [19].

Foram utilizados o Microsoft Excel 2016 e o Minitab 16 para as análises. Para valores de p inferiores a 0,05 , a hipótese nula foi rejeitada, considerando que as médias analisadas apresentaram diferenças significativas para uma confiabilidade de $95 \%$.

\section{RESULTADOS}

Na Figura 2, são apresentadas as curvas de DSC resultantes do primeiro aquecimento do PHB sob os diferentes tempos de degradação e condições de processamento, juntamente com o material virgem não degradado para o efeito comparativo. Nas respectivas curvas são observados basicamente os picos de fusão.

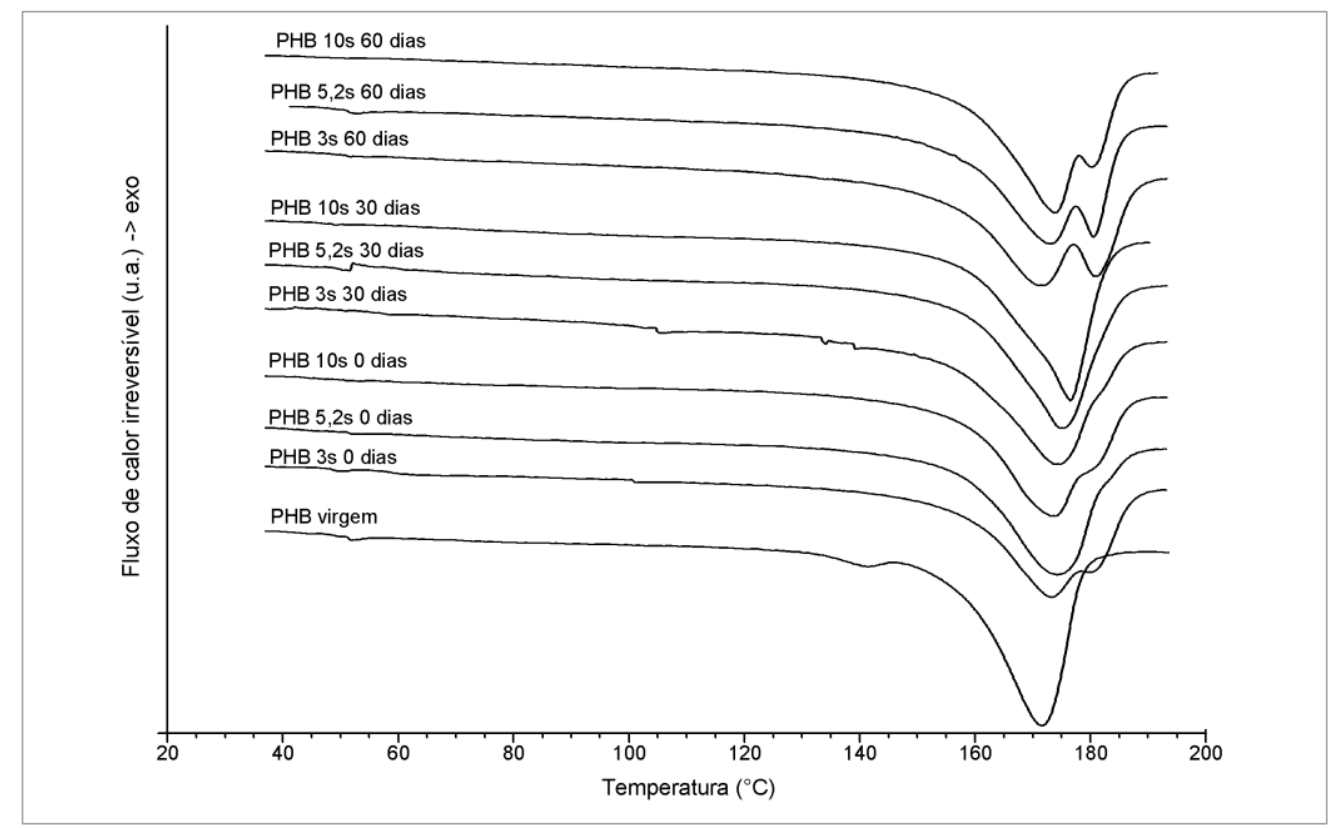

Figura 2: Curvas de DSC para o PHB após ensaio de degradação in vitro obtidas no primeiro aquecimento

Nos tempos de injeção de 3, 5,2 e 10 segundos sob a degradação de 60 dias, são observados ombros posteriores aos dos picos de fusão, com $\mathrm{T}_{\mathrm{f}}$ de aproximadamente $180^{\circ} \mathrm{C}$, os quais evidenciam a presença de cadeias poliméricas maiores que a massa molar média [20]. Sugere-se também a formação de uma estrutura cristalina diferente em relação à média. A sugestão vai ao encontro com o trabalho de Gil-Castell et. al. [27], o qual, constatou a formação de uma distribuição multimodal da massa molar do PHB em decorrência da degradação hidrolítica.

Já na Figura 3, são apresentadas as curvas resultantes do segundo aquecimento, onde são observadas as transições $T_{g}$, picos de cristalização de pré-fusão e, finalmente, os picos resultantes da fusão para cada diferente condição de processamento e tempo de degradação. 


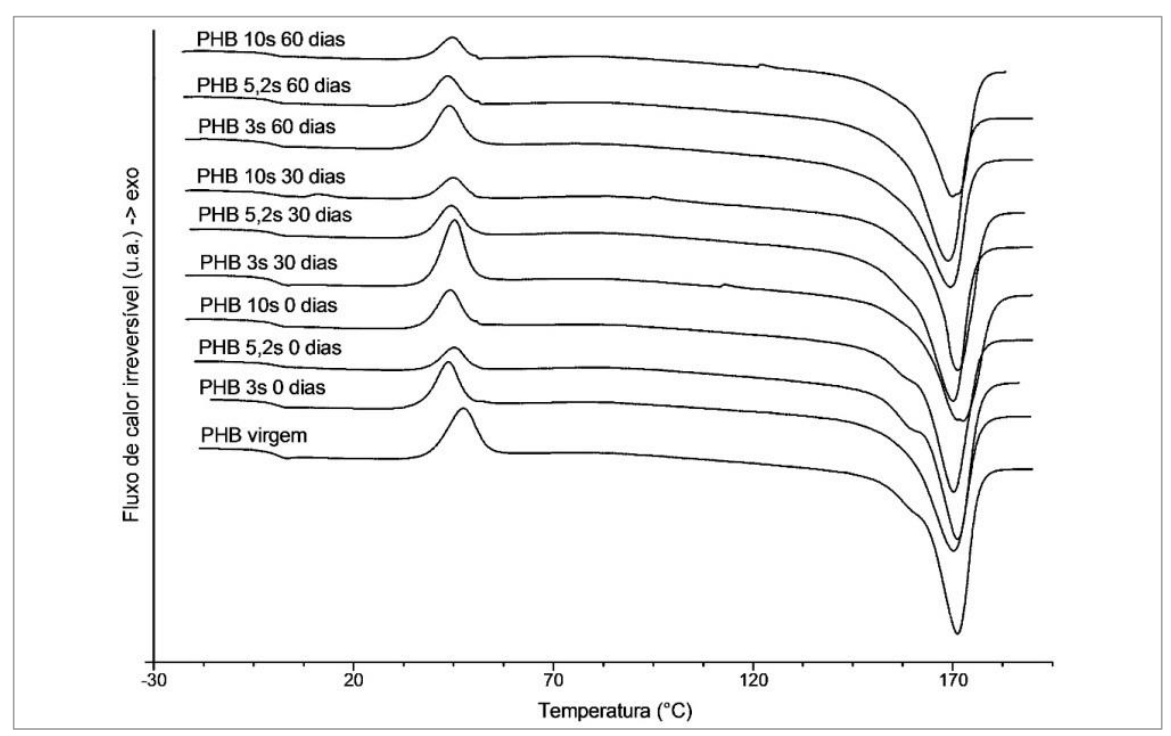

Figura 3: Curvas de DSC para o PHB após ensaio de degradação in vitro obtidas no segundo aquecimento

$\mathrm{Na}$ Tabela 2, são apresentados os resultados pormenorizados das curvas de primeiro e segundo aquecimento do PHB, juntamente com as do PHB após o ensaio de degradação, sob as diferentes condições de processamento.

\begin{tabular}{l|c|c|c|c|c|c|c|c|c}
\cline { 2 - 10 } & \multicolumn{4}{c}{ Primeiro aquecimento } & \multicolumn{5}{c}{ Segundo aquecimento } \\
\cline { 2 - 11 } & $\mathbf{T f}\left({ }^{\circ} \mathbf{C}\right)$ & $\mathbf{\Delta H f}(\mathbf{J} / \mathbf{g})$ & Cristalinidade & $\mathbf{T g}\left({ }^{\circ} \mathbf{C}\right)$ & $\mathbf{T f}\left({ }^{\circ} \mathbf{C}\right)$ & $\mathbf{\Delta H f}(\mathbf{J} / \mathbf{g})$ & $\mathbf{T c}\left({ }^{\circ} \mathbf{C}\right)$ & $\mathbf{\Delta H c}(\mathbf{J} / \mathbf{g})$ & Cristalinidade \\
\hline PHB virgem & 172 & 76 & $52 \%$ & 1 & 171 & 72 & 47 & 17 & $38 \%$ \\
\hline PHB 3s & 173 & 77 & $53 \%$ & 1 & 170 & 70 & 44 & 12 & $40 \%$ \\
\hline PHB 3s 30 dias & 174 & 84 & $58 \%$ & 0 & 173 & 76 & 45 & 19 & $39 \%$ \\
\hline PHB 3s 60 dias & 171 & 92 & $63 \%$ & 1 & 169 & 81 & 44 & 14 & $46 \%$ \\
\hline PHB 5,2s & 174 & 80 & $55 \%$ & 1 & 171 & 75 & 45 & 6 & $47 \%$ \\
\hline PHB 5,2s 30 dias & 175 & 85 & $58 \%$ & 1 & 170 & 82 & 44 & 10 & $49 \%$ \\
\hline PHB 5,2s 60 dias & 173 & 87 & $60 \%$ & 1 & 170 & 82 & 44 & 10 & $49 \%$ \\
\hline PHB 10s & 173 & 84 & $58 \%$ & 0 & 170 & 80 & 44 & 11 & $47 \%$ \\
\hline PHB 10s 30 dias & 177 & 84 & $58 \%$ & 0 & 171 & 84 & 45 & 6 & $53 \%$ \\
\hline PHB 10s 60 dias & 174 & 90 & $62 \%$ & 1 & 171 & 94 & 44 & 8 & $59 \%$ \\
\hline
\end{tabular}

Tabela 2: Resultados das curvas de DSC do primeiro e segundo aquecimento do PHB após ensaio de degradação in vitro

No primeiro aquecimento, onde o histórico das condições de processamento do material foi mantido, foram encontrados resultados no intervalo de 171 a $177^{\circ} \mathrm{C}$ para a $\mathrm{T}_{\mathrm{f}}$ e 52 a $63 \%$ na cristalinidade.

Analisando de forma individual cada diferente tempo de injeção ao longo do tempo de degradação, observou-se uma variação de $2^{\circ} \mathrm{C}$ na $\mathrm{T}_{\mathrm{f}}$ para os tempos de injeção de 3 e 5,2 segundos e $4^{\circ} \mathrm{C}$ quando o material foi injetado com o tempo de 10 segundos.

No que se refere à entalpia de fusão, constatou-se uma tendência no aumento da energia necessária para a fusão dos cristais em decorrência do aumento da cristalinidade do material, que por sua vez foi promovida pelo incremento do tempo de injeção. Nos corpos de prova injetados com 3 segundos, observou-se um incremento da cristalinidade de 53 para $63 \%$ após 60 dias em solução tampão fosfato. No tempo de injeção de 5,2 segundos, também foi observado um aumento da cristalinidade após 60 dias de degradação, variando de $55 \%$ até $60 \%$. Já no tempo de injeção de 10 segundos, onde a cristalinidade apresentada foi de $58 \%$, permaneceu inalterada após 30 dias e, finalmente, aumentou para $62 \%$ após 60 dias de degradação.

Analisando a literatura, os resultados encontrados na Tf, são compatíveis aos de $175^{\circ} \mathrm{C}$, observado no estudo de Vanin et. al. [22]. Quanto à cristalinidade, seu aumento em decorrência do tempo de degradação é atribuído a dois fatores: o primeiro fator está relacionado ao fato de polímeros semicristalinos sofrerem ataque primeiramente nas regiões amorfas, devido à maior suscetibilidade de penetração de água nestas regiões, sendo assim, a porcentagem relativa de regiões cristalinas aumenta em função do tempo de degradação. Já o segundo fator, está relacionado à cisão hidrolítica e, consequente, à formação de cadeias poliméricas de me- 
nor massa molecular, o que permite uma reorganização, permitindo a formação de novos cristais [23].

Os resultados apresentados vão ao encontro do trabalho relacionado com a degradação in vitro de blendas de PHB/PLLA, constatando um acréscimo na energia necessária para a fusão dos cristais em função do tempo de degradação, mantendo a $T_{f}$ inalterada, quando observado na composição de 100/0 [22]. Analisando pontualmente a variável do processo sendo estudada, onde, quanto menor o tempo de injeção, maior é a taxa de resfriamento do material, os resultados também vão ao encontro do estudo de Jaques et. al. [29], onde foi constatada que a fração cristalizada depende da taxa de resfriamento durante a cristalização; à medida que a taxa aumenta, a fração cristalizada diminui após a solidificação.

Na Figura 4, são apresentados os resultados pormenorizados de termogravimetria, onde $T_{i}$, representa a menor temperatura na qual foi detectada a perda de massa, enquanto $\mathrm{T}_{\text {pico }}$ se refere a temperatura máxima de degradação. Em todas as curvar a perda de massa foi na ordem de 98 a $99 \%$.

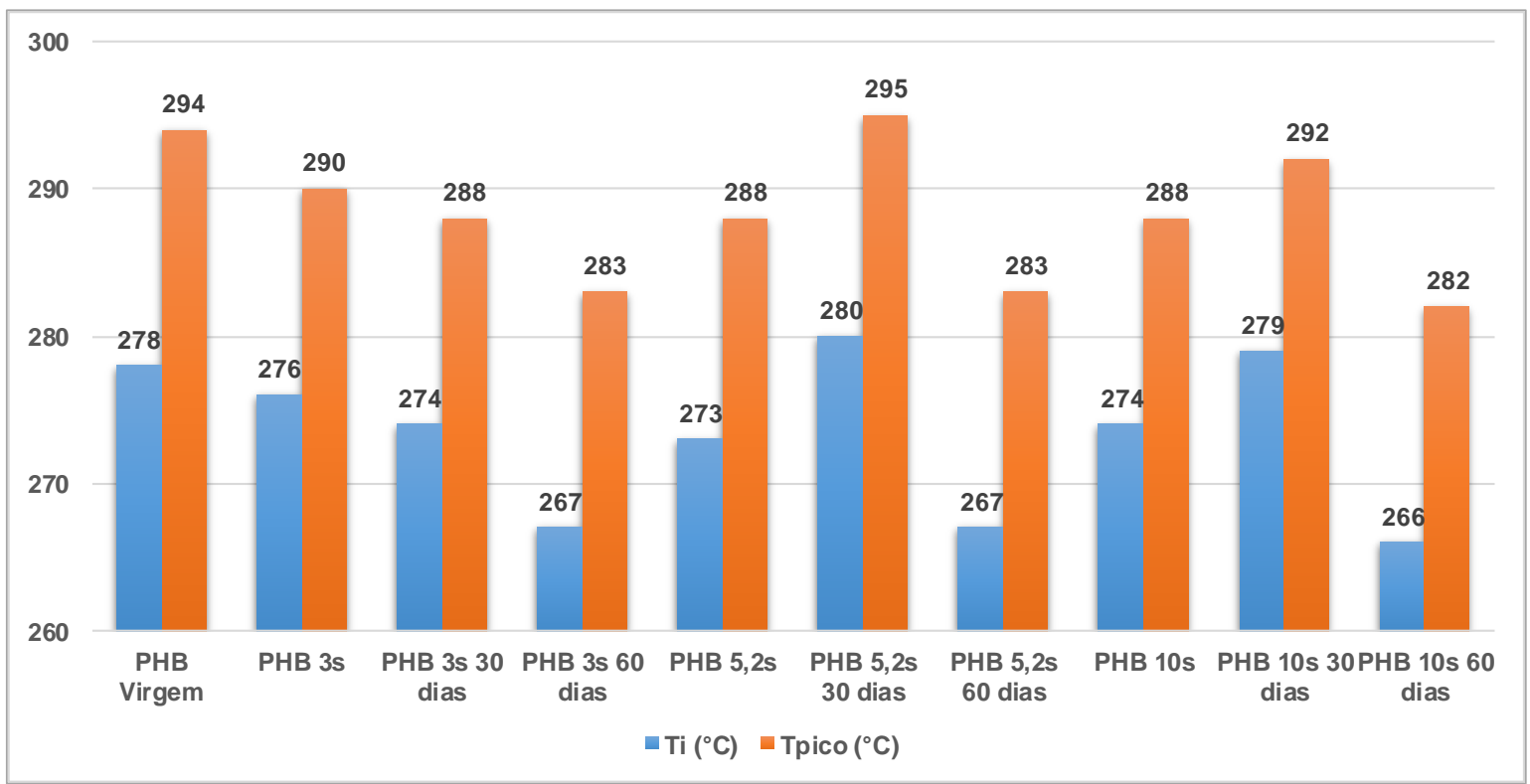

Figura 4: Resultados da análise termogravimétrica do PHB após ensaio de degradação in vitro

Analisando os resultados apresentados, no tempo de injeção de 3s, observou-se uma tendência bem definida de redução das temperaturas $T_{i}$ e $T_{\text {pico }}$, conforme o tempo de degradação era ampliado. Este mesmo comportamento foi encontrado no estudo de Gil-Castell et. al. [27], onde o PHB foi submetido à degradação in vitro sugerindo a formação de cristais imperfeitos em decorrência da degradação hidrolítica. Já nos tempos de injeção de 5,2s e 10s, observou-se um aumento nas temperaturas $T_{i}$ e $T_{\text {pico }}$ para o tempo de degradação de 30 dias e posterior redução para o tempo de degradação de 60 dias. Nos três diferentes tempos de injeção analisados, as temperaturas $T_{i}$ e $T_{\text {pico }}$ foram semelhantes para o tempo de degradação de 60 dias, sendo $267 \mathrm{e}$ $283^{\circ} \mathrm{C}$ respectivamente, o que sugeriu que a degradação do PHB, independe do tempo de injeção das amostras.

O conhecimento das propriedades térmicas e de cristalinidade são importantes, pois, através delas é possível prever e controlar uma série de características de processamento e propriedades mecânicas finais do moldado em PHB.[31]. Nos resultados das caracterizações apresentadas a seguir é possível observar a relação existente com as propriedades mencionadas.

Na Figura 5, são apresentados os resultados de tensão máxima do PHB degradado submetido aos diferentes tempos de injeção. 


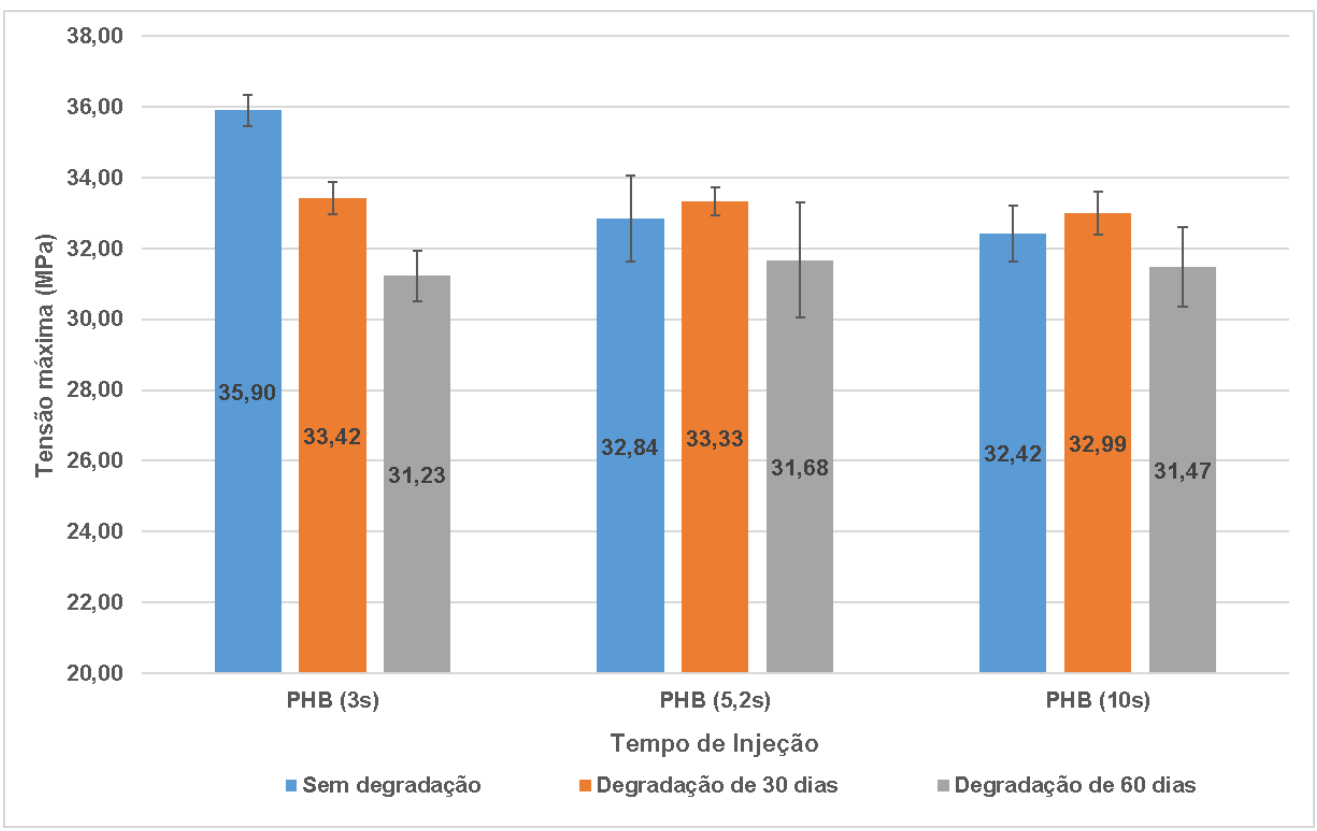

Figura 5: Resultados de tensão máxima obtidos no ensaio de tração do PHB após ensaio de degradação in vitro

Analisando os resultados, observou-se uma tendência bem definida de redução da resistência à tração ao longo do tempo de degradação, quando o material foi injetado no tempo de 3 segundos. Já nos tempos de 5,2 e 10 segundos, constatou-se um incremento na resistência à tração em 30 dias de degradação e uma diminuição da mesma no tempo de 60 dias. Na Tabela 3, são apresentados os testes estatísticos T e a análise de variância ANOVA, considerando as dispersões encontradas nos resultados dos ensaios.

\begin{tabular}{l|c|c|c|c}
\cline { 3 - 5 } \multicolumn{2}{c}{ Teste T (0 dias versus 30 dias) } & Teste T (0 dias versus 60 dias) & ANOVA \\
\hline \multirow{2}{*}{ PHB 3s } & $\mathbf{p}$ (bi-caudal) & $1,2 \times 10^{-4}$ & $1,1 \times 10^{-4}$ & $9,4 \times 10^{-7}$ \\
\cline { 2 - 5 } & $\mathbf{R}^{\mathbf{2}}$ & & & $94 \%$ \\
\hline \multirow{2}{*}{ PHB 5,2s } & $\mathbf{p}$ (bi-caudal) & $4,9 \times 10^{-1}$ & $2,7 \times 10^{-1}$ & $2,4 \times 10^{-1}$ \\
\cline { 2 - 5 } & $\mathbf{R}^{\mathbf{2}}$ & & & $27 \%$ \\
\hline \multirow{2}{*}{ PHB 10s } & $\mathbf{p}$ (bi-caudal) & $3,0 \times 10^{-1}$ & $2,9 \times 10^{-1}$ & $1,4 \times 10^{-1}$ \\
\cline { 2 - 5 } & $\mathbf{R}^{2}$ & & & $36 \%$ \\
\hline
\end{tabular}

Tabela 3: Teste estatístico nos resultados de tensão força máxima do PHB após ensaio de degradação in vitro

Tanto na análise de variância ANOVA, quanto nas duas combinações do teste $\mathrm{T}$, foram encontrados valores p inferiores a 0,05 quando o material foi processado com o tempo de 3 segundos, proporcionando, resultados significativamente diferentes do ponto de vista estatístico. Analisando o resultado de $\mathrm{R}^{2}$ (coeficiente de explicação) para o mesmo tempo de injeção, constatou-se que os diferentes tempos de degradação proporcionaram elevada influência nos resultados de resistência à tração.

Nos tempos de injeção de 5,2 e 10 segundos, os valores de p encontrados foram superiores a 0,05 , evidenciando assim, que as diferenças encontradas nos resultados não foram significativas. Os resultados de $\mathrm{R}^{2}$ revelaram pouca relação entre o tempo de injeção e o tempo de degradação nos resultados obtidos.

Considerando a variação da cristalinidade encontrada nos resultados do DSC, sugere-se uma relação da alteração das propriedades de tração concomitantemente com o aumento da cristalinidade e a perda de massa molar. Conforme literatura, as regiões amorfas são primeiramente afetadas pela degradação hidrolítica, ocasionando redução da massa molar e consequente redução das propriedades mecânicas de tração. De acordo com o estudo de Kunze et. al. [24], envolvendo o PHB com massa molar numérica média de 600.000 $\mathrm{g} / \mathrm{mol}$, submetido à degradação in vitro ao longo de dois anos, observou-se que nos tempos de 30 e 60 dias, o material apresentou perda de massa molar aproximada de 5 e $8 \%$ respectivamente, chegando a $45 \%$ após um ano e $65 \%$ ao final do segundo ano. Sendo assim, observa-se uma relação direta com a redução das propriedades de tração em decorrência do aumento da cristalinidade de $18,9 \%$ e perda de massa molar quando o material foi injetado com o tempo de 3 segundos. Esta constatação também está de acordo com os resultados de $\mathrm{TG}$, pois as temperaturas $\mathrm{T}_{\mathrm{i}}$ e $\mathrm{T}_{\text {pico }}$ também foram reduzidas conforme o tempo de degradação avançava. 
Já nos tempos de injeção de 5,2 e 10 segundos, onde o comportamento apresentado foi distinto em relação ao de 3 segundos, apontando pouca significância do ponto de vista estatístico, sugere-se também uma relação com a variação da cristalinidade, comparativamente menor, apresentada de $9,1 \%$ e $6,9 \%$ nesta ordem após 60 dias de degradação e com a perda de massa molecular, aliada a um princípio de degradação térmica encontrado nos resultados de TG identificada à medida que o tempo de injeção era ampliado. Ainda, sugerese que o aumento nas temperaturas $\mathrm{T}_{\mathrm{i}}$ e $\mathrm{T}_{\text {pico }}$ após 30 dias, seguido de uma posterior redução, após 60 dias de degradação, refletiram nas propriedades mecânicas de tração.

Além da cristalinidade e da degradação térmica, outra característica do PHB que também interfere nas propriedades mecânicas é o tamanho dos esferulitos resultante do processo de cristalização. A baixa nucleação, aliada a uma baixa taxa de resfriamento, promovem o crescimento excessivo dos esferulitos. Tensões são geradas durando o processo de resfriamento, ocasionando fissuras radiais e circunferenciais interferindo negativamente na resistência à tração e nas demais propriedades mecânicas [28, 29, 33].

Na Figura 6 são apresentadas imagens da microscopia óptica com luz polarizada extraídas dos corpos de prova de tração sem degradação.

a)

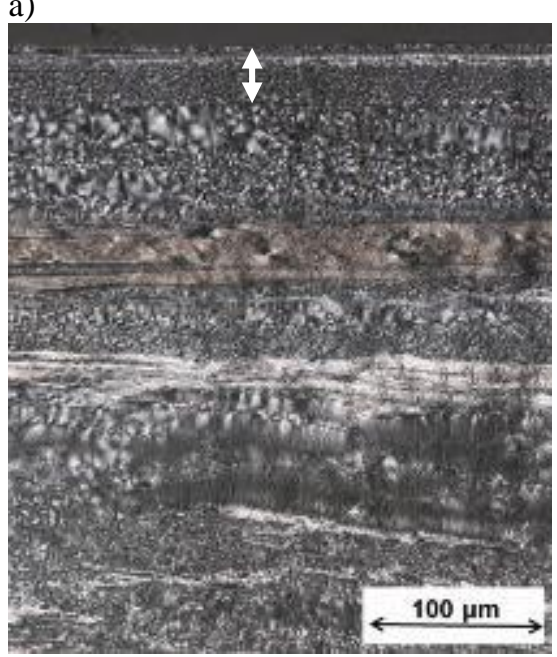

b)

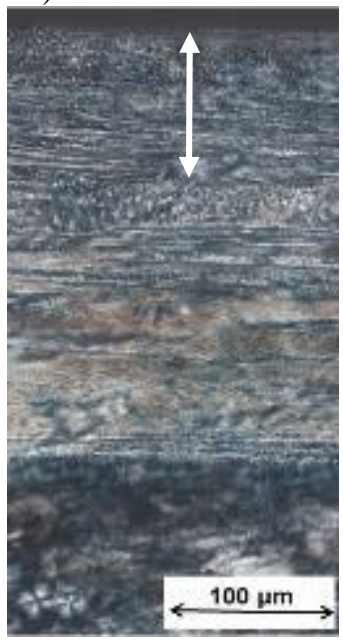

c)

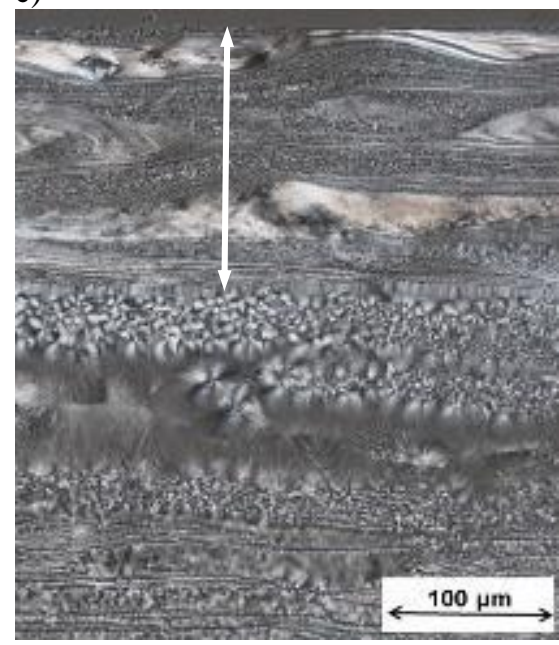

Figura 6: Imagens da microscopia óptica com luz polarizada do PHB 100x: a) 3s; b) 5,2s e c) 10s sem degradação

No tocante à camada congelada, observou-se uma espessura na ordem de $30 \mu \mathrm{m}$ no tempo de injeção de 3 segundos (Figura 6a), no tempo de injeção de 5,2 segundos (Figura 6b), a espessura apresentou-se com dimensão aproximada de $100 \mu \mathrm{m}$. Já no tempo de preenchimento de 10 segundos (Figura 6c), a espessura da camada foi ampliada para $155 \mu \mathrm{m}$. Os resultados encontrados foram compatíveis com os da literatura, onde, o aumento da espessura da camada congelada é proporcional ao aumento do tempo de injeção. Quando o tempo de injeção é ampliado, menor quantidade de calor é gerado por atrito e, consequentemente, maior quantidade de calor perdido por condução ocasionando um aumento da espessura dessa camada [9, 10].

Com relação aos esferulitos, no tempo de injeção de 3 segundos, as estruturas apresentaram-se posicionadas próximas à superfície do moldado. À medida que o tempo de injeção foi ampliado, os esferulitos foram afastados da superfície, apresentando uma tendência de serem maiores. Nos diferentes tempos de injeção, são observadas camadas compostas por diferentes tamanhos de esferulitos, onde sugere-se diferentes níveis de orientação molecular, os quais, proporcionaram diferentes trocas térmicas influenciando no tamanho das estruturas esferulíticas. O tamanho e quantidade de cristalitos dentro de um esferulito, bem como o tamanho de cada esferulito, depende da velocidade de cristalização do polímero, da velocidade da formação dos núcleos e da mobilidade das moléculas. A temperatura e o tempo de cristalização são os parâmetros que governam a cristalização, influenciando na porcentagem, no tamanho e na distribuição dos tamanhos dos cristais [10].

Na Figura 7, são apresentadas as imagens obtidas por meio da microscopia eletrônica de emissão de campo nas superfícies de fratura, após ensaio de tração do PHB degradado no tempo de 60 dias. 
a)

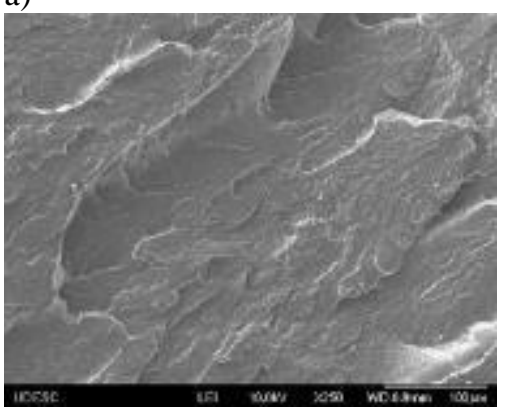

b)

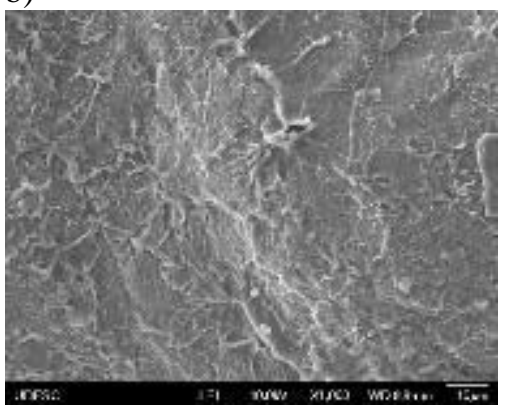

c)

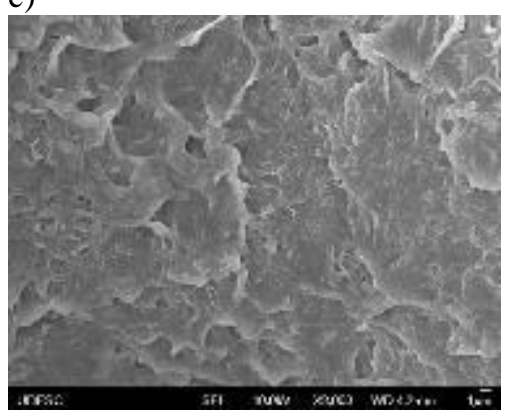

d)

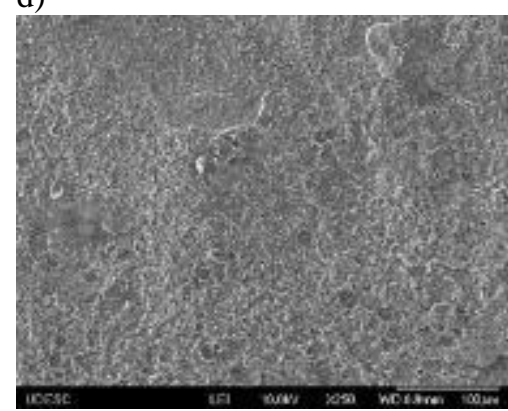

e)

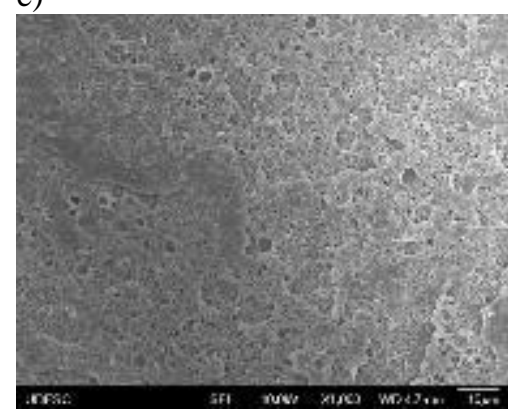

f)

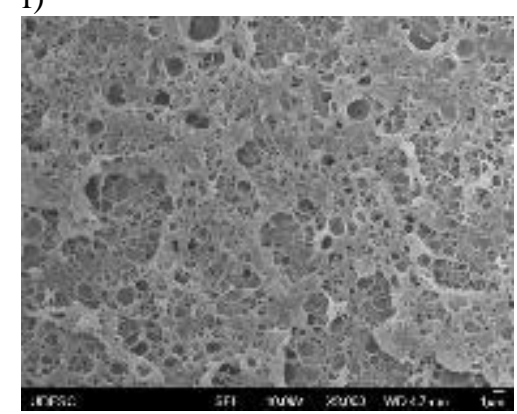

g)

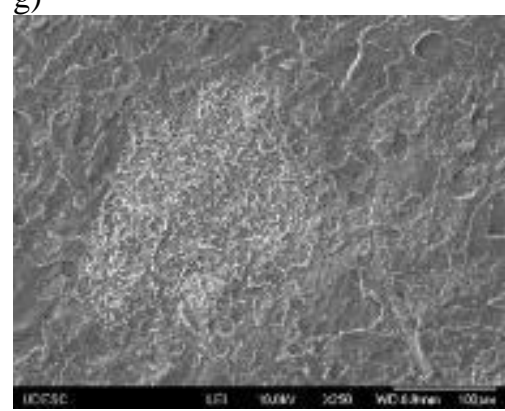

h)

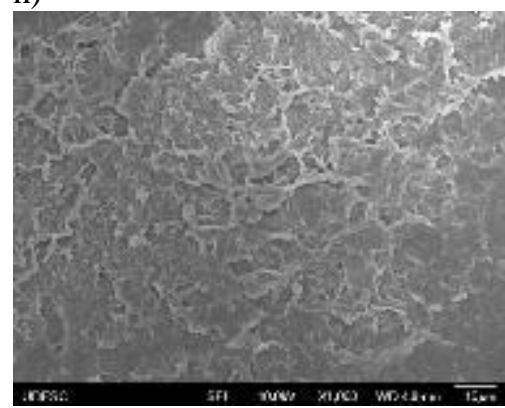

i)

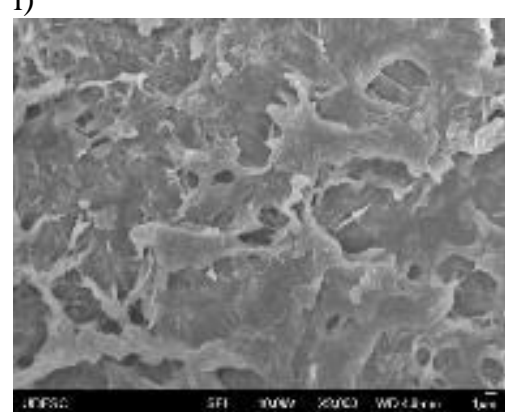

Figura 7: Micrografias de superfície de fratura de tração do PHB após ensaio de degradação in vitro no tempo de 60 dias: a) 3s 250x; b) 3s 1000x; c) 3s 3000x; d) 5,2s 250x; e) 5,2s 1000x; f) 5,2s 3000x; g) 10s 250x; h) 10s 1000x e i) 10s $3000 x$

Analisando as imagens, observam-se evidências de degradação hidrolítica nas superfícies de fratura dos corpos de prova de tração, processados nos três diferentes tempos de injeção. No tempo de 3 segundos (Figuras 7a, 7b e 7c), a degradação é apresentada em regiões concentradas ao longo da superfície da fratura, conforme pode ser verificada na Figura 7b. Já no tempo de 5,2 segundos (Figuras 7d, 7e e 7f), toda a superfície da fratura foi atingida pela degradação. No tempo de injeção de 10 segundos (Figuras $7 \mathrm{~g}, 7 \mathrm{~h}$ e $7 \mathrm{i}$ ), a degradação também é apresentada em regiões concentradas como no tempo de 3 segundos, porém em tamanhos maiores.

Conforme destacado anteriormente, a degradação hidrolítica é iniciada primeiramente nas regiões amorfas do polímero, onde a difusão e penetração de água é facilitada. Posteriormente, quando grande parte das regiões amorfas foram consumidas, a degradação prossegue nas regiões cristalinas do material. Conforme Asrar and Hill [30], a degradação do PHB produz o ácido 3-hidroxibutírico, o qual é um constituinte presente no sangue humano. Desta forma, o material pode ser empregado em aplicações biomédicas.

Na Figura 8, são apresentados os resultados do ensaio de impacto Izod das amostras de PHB degradadas nos tempos de 0, 30 e 60 dias. Analisando a média dos resultados, nos três diferentes tempos de injeção observou-se um acréscimo na resistência após 30 dias de degradação, seguida de uma posterior redução após 60 dias. 


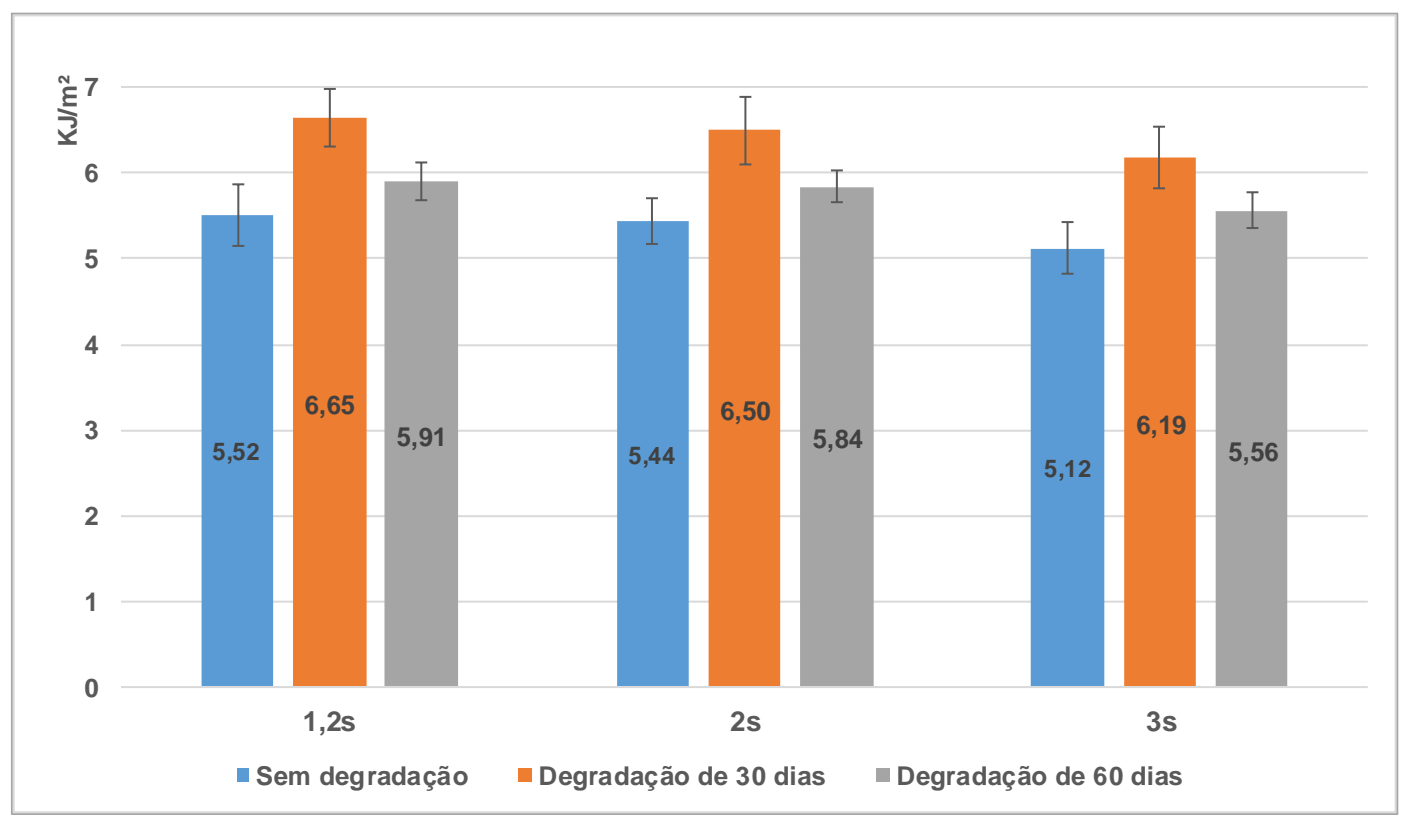

Figura 8: Resultados do Ensaio de Impacto do PHB após ensaio de degradação in vitro

Na Tabela 4, são apresentados os resultados dos testes estatísticos T e da análise de variância ANOVA.

\begin{tabular}{l|c|c|c|c}
\cline { 3 - 5 } \multicolumn{2}{c}{} & Teste T (0 dias versus 30 dias) & Teste T (0 dias versus 60 dias) & ANOVA \\
\hline \multirow{2}{*}{ PHB 1,2s } & $\mathbf{p}$ (bi-caudal) & $5,7 \times 10^{-5}$ & $5,7 \times 10^{-2}$ & $1,3 \times 10^{-5}$ \\
\cline { 2 - 5 } & $\mathbf{R}^{\mathbf{2}}$ & & & $57 \%$ \\
\hline \multirow{2}{*}{ PHB 2s } & $\mathbf{p}$ (bi-caudal) & $1,0 \times 10^{-4}$ & $1,1 \times 10^{-2}$ & $1,5 \times 10^{-5}$ \\
\cline { 2 - 5 } & $\mathbf{R}^{\mathbf{2}}$ & & & $56 \%$ \\
\hline \multirow{2}{*}{ PHB 3s } & $\mathbf{p}$ (bi-caudal) & $8,7 \times 10^{-5}$ & $1,5 \times 10^{-2}$ & $2,0 \times 10^{-5}$ \\
\cline { 2 - 5 } & $\mathbf{R}^{\mathbf{2}}$ & & & $55 \%$ \\
\hline
\end{tabular}

Tabela 4: Teste estatístico nos resultados de impacto do PHB após ensaio de degradação in vitro

Verificando os resultados do teste $\mathrm{T}$, o qual analisou os resultados em pares e da análise de variância ANOVA que, por sua vez, verificou simultaneamente os três tempos de degradação para cada diferente velocidade de injeção, observou-se que os resultados de p em praticamente todos os testes foi inferior a 0,05 , considerando assim os mesmos significativamente diferentes. A única exceção apresentada foi para o teste T no tempo de 1,2 segundos na combinação da degradação de 0 versus 60 dias, o qual apresentou um valor de $p$ igual a 0,06. Já os valores encontrados de $\mathrm{R}^{2}$, os quais variaram entre 55 e $57 \%$, identificaram a influência que os diferentes tempos de degradação promoveram nos resultados de impacto.

Correlacionado com os resultados obtidos no DSC, onde o avanço no tempo de degradação proporcionou um aumento na cristalinidade do PHB e de acordo com a literatura, o aumento da cristalinidade do PHB ocasiona aumento do módulo de elasticidade e diminuição da resistência ao impacto [25].

Com relação ao comportamento observado, sugere-se apresentar algumas hipóteses baseadas nas duas etapas da degradação hidrolítica. Na primeira etapa, ocorrida durante a exposição do PHB nos primeiros 30 dias à solução tampão fosfato, ocorreu a cisão hidrolítica das cadeias pertencentes prioritariamente às regiões amorfas, que proporcionou a formação de novos cristalitos com diâmetros menores em relação à primeira cristalização. Cristalitos menores circundados por regiões amorfas permitiram absorver uma maior quantidade de energia proveniente do impacto que o comparado com o material não submetido ao procedimento de degradação. Já no segundo estágio, compreendido no período de 30 e 60 dias, onde grande parte da região amorfa foi anteriormente consumida, iniciou-se a cisão hidrolítica das cadeias poliméricas formadoras dos cristalitos previamente organizados, como também das estruturas provenientes da primeira cristalização, dessa forma, reduzindo a resistência ao impacto em relação ao estágio anterior [26, 27].

Caso o processo de degradação continuasse além dos 60 dias, a resistência ao impacto seria continuamente reduzida, pois a quantidade de regiões amorfas seria cada vez mais escassa em uma matriz cristalina 
sendo submetida a degradação hidrolítica.

Na Figura 9, são apresentados os resultados médios do ensaio de dureza extraídos nas cinco diferentes regiões dos corpos de prova.

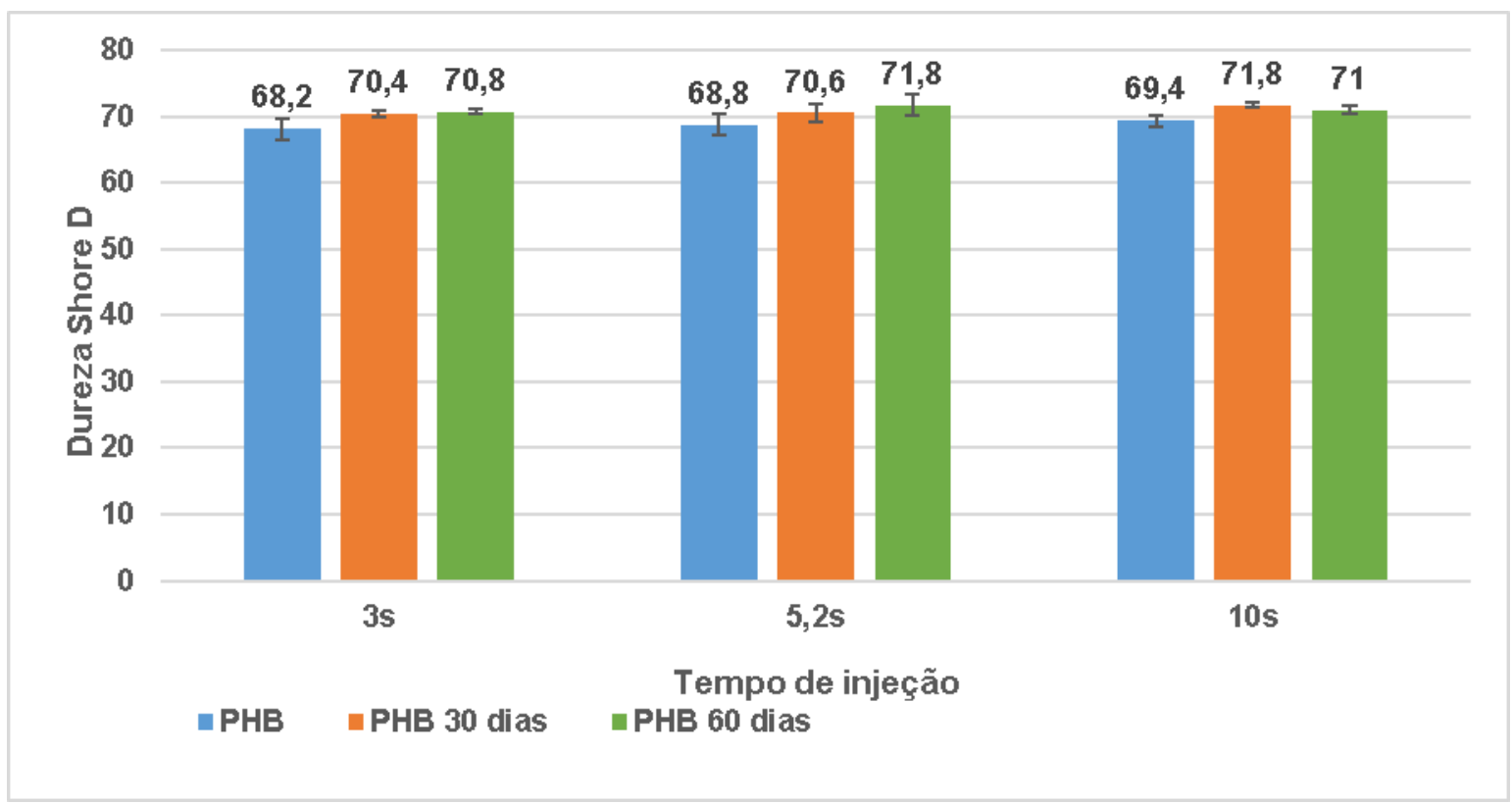

Figura 9: Resultados do ensaio de dureza Shore D nas diferentes regiões do corpo de prova do PHB após ensaio de degradação in vitro

Analisando a média dos resultados, observou-se uma sensível tendência no aumento da dureza em função do aumento do tempo de injeção e do tempo de degradação. Na Tabela 5, são apresentados os resultados dos testes estatísticos T e a análise de variância ANOVA, considerando o tempo de degradação para cada diferente tempo de injeção.

\begin{tabular}{l|c|c|c|c}
\cline { 3 - 5 } \multicolumn{2}{c}{} & Teste T (0 dias versus 30 dias) & Teste T (0 dias versus 60 dias) & ANOVA \\
\hline \multirow{2}{*}{ PHB 3s } & $\mathbf{p}$ (bi-caudal) & $4,7 \times 10^{-2}$ & $3,4 \times 10^{-2}$ & $6,3 \times 10^{-3}$ \\
\cline { 2 - 5 } & $\mathbf{R}^{\mathbf{2}}$ & & & $57 \%$ \\
\hline \multirow{2}{*}{ PHB 5,2s } & $\mathbf{p}$ (bi-caudal) & $1,2 \times 10^{-1}$ & $2,9 \times 10^{-2}$ & $4,9 \times 10^{-2}$ \\
\cline { 2 - 5 } & $\mathbf{R}^{\mathbf{2}}$ & & & $40 \%$ \\
\hline \multirow{2}{*}{ PHB 10s } & $\mathbf{p}$ (bi-caudal) & $1,7 \times 10^{-3}$ & $1,4 \times 10^{-2}$ & $5,6 \times 10^{-4}$ \\
\cline { 2 - 5 } & $\mathbf{R}^{\mathbf{2}}$ & & & $71 \%$ \\
\hline
\end{tabular}

Tabela 5: Teste estatístico nos resultados de dureza do PHB após ensaio de degradação in vitro

Observando os resultados dos testes estatísticos, com exceção do tempo de 5,2 segundos na combinação de 0 versus 30 dias, todos os demais resultados apontaram diferenças significativas na dureza em função do tempo de degradação. Os resultados de $\mathrm{R}^{2}$, os quais variaram entre $40 \%$ e $71 \%$ indicaram a influência que a degradação promoveu nos resultados de dureza.

Analisando, conjuntamente, os valores obtidos no ensaio de dureza e os valores de DSC, observou-se uma relação direta do aumento da dureza com o aumento da cristalinidade do PHB, a qual pode ser confirmada pela literatura, onde a maior presença de regiões cristalinas no material oferecem uma maior resistência à indentação [10].

Vale destacar que o PHB sofre cristalização secundária após seu processamento e moldagem em função da mobilidade existente na região amorfa, em temperaturas acima da $\mathrm{T}_{\mathrm{g}}$, atingindo estabilidade em torno de 20 dias. A cristalização secundária promove o aumento da cristalinidade do material, afetando assim as propriedades mecânicas como tração, impacto, dureza e aumento do módulo de elasticidade [17-32]. 


\section{CONCLUSÕES}

Através do estudo, pode-se observar a influência do tempo de injeção nas propriedades mecânicas, morfológicas e térmicas do PHB, bem como, analisar a influência que os diferentes tempos de injeção promoveram no processo de degradação in vitro do material.

Observou-se que diferentes tempos de injeção influenciaram nas propriedades mecânicas, morfológicas e térmicas do PHB, sendo possível o ajuste das propriedades do material por meio do processo de injeção. Os resultados também demonstraram que a variação da referida variável de processamento influenciou no processo de degradação in vitro do material, sendo encontradas diferenças mais significativas nos menores tempos de injeção, sendo, 1,2 e 3 segundos, respectivamente, nos ensaios de impacto e tração. A exceção ficou por conta dos resultados de dureza shore $\mathrm{D}$, colhidos a partir dos corpos de prova injetados com o tempo de 10 segundos. Nos resultados de impacto, foi observado um acréscimo de $20,47 \%$, seguido de uma redução de 11,13\% na propriedade, respectivamente, para os tempos de 30 e 60 dias de degradação. Já nos resultados de tensão máxima, observou-se uma redução de 6,91\% em 30 dias e $13 \%$ em 60 dias de degradação comparado com o material não degradado. Nos resultados de dureza shore $\mathrm{D}$, foi observado um acréscimo de $3,46 \%$ e uma posterior redução de $1,11 \%$ na propriedade, basicamente, influenciado pela variação de cristalinidade e do processo de cisão hidrolítica no material.

Neste contexto, conclui-se que a variação do tempo de injeção proporciona um ajuste de propriedades no moldado, em decorrência de ocasionar diferentes taxas de resfriamento e orientação molecular, interferindo, desta forma, na cinética de cristalização. Ainda, o estudo possibilita ampliar o campo de utilização de um polímero proveniente de fontes renováveis, além de explorar suas características biorreabsorvíveis comprovadas. Em suma, por meio do controle das propriedades mecânicas e morfológicas, concomitantemente com o processo de regeneração da região implantada. A cristalinidade de um suporte temporário produzido em PHB pode ser ajustada de acordo com a taxa de degradação requerida na aplicação.

\section{AGRADECIMENTOS}

Os autores agradecem ao PROGRAMA UNIEDU PÓS-GRADUAÇÃO, pela bolsa de estudo; à UNISOCIESC, pela bolsa de estudos e pelo auxílio nas diversas caracterizações realizadas e à Biocycle, pela doação do PHB.

\section{BIBLIOGRAFIA}

[1] TIAN, H., TANG, Z., ZHUANG, X., et al., "Biodegradable synthetic polymers: Preparation, functionalization and biomedical application", Progress in Polymer Science, v. 37, 237-280, 2012.

[2] SILVA, L. F., et al., "Produção biotecnológica de poli-hidroxialcanoatos para a geração de polímeros biodegradáveis no Brasil”, Quím. Nova, São Paulo, v. 30, n. 7, p. 1732-1743, 2007.

[3] WELLEN, R.M.R., et al., "Photodegradation and Photostabilization of Poly(3-Hydroxybutyrate)", Mat. Res., São Carlos, v. 19, n. 4, p. 759-764, ago. 2016.

[4] JAQUES, N.G., et al., "Comparative study of the effect of $\mathrm{TiO} 2$ and $\mathrm{ZnO}$ on the crystallization of PHB", Matéria (Rio J.), Rio de Janeiro, v. 22, n. 4, e-11880, 2017.

[5] QUENTAL, A.C.et al., "Blendas de PHB e seus copolímeros: miscibilidade e compatibilidade", Quím. Nova, São Paulo, v. 33, n. 2, 2010.

[6] REIS, E.C.C., et al., "Desenvolvimento e caracterização de membranas rígidas, osteocondutoras e reabsorvíveis de polihidroxibutirato e hidroxiapatita para regeneração periodontal”, Polímeros, São Carlos, v. 22, n. 1, 2012.

[7] DOMÍNGUEZ-DÍAZ, M., et al., "Thermo-mechanical properties, microstructure and biocompatibility in poly- $\beta$-hydroxybutyrates (PHB) produced by OP and OPN strains of Azotobacter vinelandii", European Polymer Journal, v. 63, p. 101-112, 2015.

[8] PACHEKOSKI, W.M., DALMOLIN, C., AGNELLI, J.A.M., "The influence of the industrial processing on the degradation of poly(hidroxybutyrate) - PHB”, Mat. Res., São Carlos, v. 16, n. 2, p. 237-332, Apr.

2013. 
[9] ALMEIDA, A.M., BRANCIFORTI, M.C., BRETAS, R.E.S., "Avaliação da orientação molecular de moldados de polipropileno utilizando figuras de pólo obtidas por difração de raios X", Polímeros: Ciência e Tecnologia, v. 17, n. 1, p. 28, 2007.

[10] MANRICH, S.. Processamento de Termoplásticos: rosca única, extrusão e matrizes, injeção e moldes. $2^{\mathrm{a}}$ ed. São Paulo: Artiber Editora, 2013.

[11] ROSA, D.S., PANTANO FILHO, R. Biodegradação: um ensaio com polímeros. Bragança Paulista, Sp: Moara, 2003. 112 p.

[12] WELLEN, R.M.R., et al., "Melting and crystallization of poly (3-hydroxybutyrate): effect of heating/cooling rates on phase transformation. Polímeros", v. 25, n. 3, p. 296-304, 2015.

[13] DOS SANTOS, A.J., et al. "From Obtaining to Degradation of PHB: A Literature Review. Part II", Ing.Cienc., Medellín, v. 14, n. 27, p. 207-228, June 2018.

[14] DI LORENZO, M.L., RIGHETTI, M.C. "Effect of thermal history on the evolution of Crystal and amorphous fractions of poly[(R)-3-hydroxybutyrate] upon storage at ambient temperature", European Polymer Journal, Volume 49, Issue 2, 2013.

[15] MOTTIN, A.C., et al., "What Changes in Poly(3-Hydroxybutyrate) (PHB) When Processed as Electrospun Nanofibers or Thermo-Compression Molded Film?” Mat. Res., São Carlos, v. 19, n. 1, p. 57-66, fev. 2016.

[16] VROMAN, I., TIGHZERT, L., "Biodegradable polymers", Materials, v. 2, n. 2, p. 307-344, 2009.

[17] MELLO, C.C., COSTA, M.F., THIRÉ, R.M.S.M., "Avaliação do efeito da cristalização secundária em compósitos de polihidroxibutirato e pó de coco silanizado", $11^{\circ}$ Congresso Brasileiro de Polímeros, Campos do Jordão - SP, 2011

[18] BARBETTA, P.A., Estatística aplicada às ciências sociais. 8. ed. Florianópolis: Editora da UFSC, 2012. [19] MONTGOMERY, D.C.., RUNGER, G.C., Estatística aplicada e probabilidade para engenheiros. $4^{\mathrm{a}}$ ed. Rio de Janeiro: LTC, 2009.

[20] ROSA, D.S., PENTEADO, D.F., CALIL, M.R., "Propriedades Térmicas e Biodegradabilidade de PCL e PHB em um Pool de Fungos", Polímeros: Ciência e Tecnologia, v. 15, p. 75-80, 2000.

[21] BARHAM, P.J., et al., "Crystallization and morphology of a bacterial thermoplastic: poly-3hydroxybutyrate", Journal of Materials Science, v. 19, n. 9, p. 2781-2794, 1984.

[22] VANIN, M., et al., "Estudo da Degradação "In Vitro" de Blendas de Poli (beta-Hidroxibutirato) (PHB)/Poli (L-Acido Latico)(PLLA) na Forma de Filmes", Polímeros: Ciência e Tecnologia, v. 14, p. 187193, 2004.

[23] MOTTA, A.C., DUEK, E.A.R., "Síntese, caracterização e degradação" in vitro" do poli (L-ácido lácticoco-ácido glicólico)", Revista Matéria, v. 11, n. 3, p. 340-350, 2006.

[24] KUNZE, C., et al., "In vitro and in vivo studies on blends of isotactic and atactic poly (3hydroxybutyrate) for development of a dura substitute material", Biomaterials, v. 27, n. 2, p. 192-201, 2006.

[25] TADA, E.S., "Blendas com poli(3-hidroxibutirato) (PHB) e copolímeros aleatórios: comportamento de fases e cinética de cristalização" Tese (Doutorado em Ciências), Curso de Ciências, Físico-química, Universidade Estadual de Campinas, Campinas, 2009.

[26] BARBANTI, S.H., ZAVAGLIA, C.A.C.; DUEK, E.A.R., "Polímeros biorreabsorvíveis na engenharia de tecidos", Polímeros, São Carlos, v. 15, n. 1, Mar. 2005.

[27] GIL-CASTELL, O. et al., "Performance of Polyester-Based Electrospun Scaffolds under In Vitro Hydrolytic Conditions: From Short-Term to Long-Term Applications", Nanomaterials, v. 9, n. 5, p. 78622 May 2019.

[28] JAQUES, N.G., et al., "Comparative study of the effect of $\mathrm{TiO} 2$ and $\mathrm{ZnO}$ on the crystallization of PHB", Matéria (Rio J.), Rio de Janeiro, v. 22, n. 4, e-11880, 2017.

[29] YEO, J.C.C., et al., "Recent advances in the development of biodegradable PHB-based toughening materials: Approaches, advantages and applications", Materials science \& engineering. C, Materials for biological applications v. 92, 2018.

[30] ASRAR, J., HILL, J.C. "Biosynthetic processes for linear polymers", Journal of applied polymer science, v. 83 , n. 3, p. 457-483, 2002. 
[31] MCADAM, B., et al., "Production of Polyhydroxybutyrate (PHB) and Factors Impacting Its Chemical and Mechanical Characteristics." Polymers v. 12,12 2908. 4 Dec. 2020.

[32] LOPERA-VALLE, A. et al., "Influence of Epoxidized Canola Oil (eCO) and Cellulose Nanocrystals (CNCs) on the Mechanical and Thermal Properties of Polyhydroxybutyrate (PHB)-Poly(lactic acid) (PLA) Blends." Polymers v. 11,6 933. 29 May. 2019.

[33] LU, X., WEN, X.. YANG, D.. Isothermal crystallization kinetics and morphology of biodegradable poly (3-hydroxybutyrate-co-4-hydroxybutyrate). Journal of Materials Science, v. 46, n. 5, p. 1281-1288, 2011.

\section{ORCID}

Marcio Briesemeister

Katiusca Wessler

Márcia Adriana Tomaz Duarte https://orcid.org/0000-0003-0707-3176

http://orcid.org/0000-0003-2335-3784

http://orcid.org/0000-0002-4428-4725 